\title{
Zipf's Law and the Gibrat's Law: What Do the Facts Have to Say about the Brazilian Cities?
}

\author{
Wellington Ribeiro Justo* \\ Department of Economics, Regional University of Cariri (URCA), Crato (CE), Brazil \\ *Corresponding author: justowr@yahoo.com.br
}

Received March 21, 2014; Revised April 04, 2014; Accepted May 03, 2014

\begin{abstract}
Despite attempts to relate the economic theory with the statistical data, the theory is usually sufficiently clear, supplying simple and well-defined forecasts, whilst the real world tends to produce complicated and disorganized results. However, with reference to models on the distribution of city sizes the inverse occurs. That is; the data, surprisingly offers a sufficiently clear picture with high degrees of difficulty of being reproduced theoretically. This work aims at verifying whether two of the most well known and intriguing phenomena, Zipf's Law and Gibrat's Law, occur in Brazil, and also to make a theoretical analysis of such phenomena. The study uses the Brazilian demographic census data of 1970, 1980, 1991 and 2000 and the 1996 population counting. The results confirm that these empirical regularities indeed occur in the distribution of the Brazilian cities.
\end{abstract}

Keywords: Gibrat's law, New Economic Geography, the distribution of city sizes, Zipf's law

Cite This Article: Wellington Ribeiro Justo, “Zipf's Law and the Gibrat's Law: What Do the Facts Have to Say about the Brazilian Cities?” Journal of Finance and Economics, vol. 2, no. 5 (2014): 136-144. doi: 10.12691/jfe-2-5-1.

\section{Introduction}

From a historical perspective, the cities emerged in several parts of the world around seven thousand years ago because of the increase of agricultural surplus. The existence of the cities can be seen like a universal phenomenon whose importance, slowly but continuously, has increased during the centuries that preceded the sudden urban growth during the nineteen century in Europe. The technological development was necessary to produce the agricultural surplus without which the cities would have not been possible (FUJITA AND THISSE, 2002).

Further to the technological innovations, a fundamental change in the social structure was necessary: the division of the work in specialized activities. In this sense, it appears to be an agreement amongst economists, geographers and historians upon considering increasing returns as the most critical factor in the emergence of the cities. Although the sources are scattered and, not always comparable, the facts converge in presetting the existence of an urban revolution. In Europe, the proportion of persons living in the cities increased from $10 \%$ in 1300 to $12 \%$ in 1800 (Bairoch, 1993). In 1950, it reached nearly $75 \%$. After that period, the concentration in big cities continued to increase.

Others factors that have influenced the population concentration in the cities are the increase in the availability of high-speed transports and the rapid development of new information technologies. These phenomena suggest that the economies are entering a new era that will culminate with the so-called "death of the distance". If this were true, locational differences would gradually diminish because the agglomeration forces could disappear. Instead of that, a general principle can be derived from this analysis, that there is a relationship between decrease in the costs of transport and the degree of agglomeration economic activities. There are, however, other acting forces involved, mainly the increasing returns and the external diseconomies. Intuitively, it would be naive to suppose that the spatial configuration of the activities is a product of the action of two opposite forces, namely, agglomeration (centripetal) and dispersion (centrifuges). The surge of the cities also relied on other components such as the unequal distribution of the natural resources, for instance.

As it has been shown by many historians and theoreticians of development, the economic growth tends to be localized. This phenomenon is spatially well distributed by the rapid growth of East Asia during the last two decades of the past century. In 1990, the East Asian population was around 1.6 billion of people with barely $3.5 \%$ of the geographical area and $7.9 \%$ of the total population; Japan accounts for $72 \%$ of the gross domestic product (GDP) (Fujita and Thisse, 2002).

Still according to the same authors, strong regional disparities inside the same country imply the existence of collections in a spatial scale, for example, in Korea. The capital region of Seoul and the province of Kyungki represent $11.8 \%$ of the total area of the country with $45.3 \%$ of the population and produced $46.2 \%$ of GDP. The Île-de-France, metropolitan region of Paris, represents barely $2.2 \%$ of the French territory and $18.9 \%$ of the population but produced $30 \%$ of its GDP. The city of São 
Paulo represents around $0.2 \%$ of the geographical area of the Brazilian territory and was responsible for around $10,41 \%$ of GDP of Brazil in 2002, representing only around $6.15 \%$ of the Brazilian population. ${ }^{1}$

Agglomerations also reflect a large variety of cities, as shown by the stability of urban hierarchy inside the majority of countries (Dobkins and Ioannides, 2000). Cities can also be specialized in a number of industries, like many medium-size American cities (Henderson, 1997). However, big megalopolis such as New York and Tokyo are highly diversified and involve many industries that are linked through direct connections (Fujita and Tabuchi, 1997).

Analyzing the possible spectrum of explanations for the emergence of agglomerations, they appear in diverse forms: large commercial, industrial and leisure districts. The understanding of such phenomenon is important for the planning of public policies.

In this sense, the distribution of city sizes has been widely explored in the literature. Two of the most wellknown and intriguing phenomena are the Zipf's law and the Gibrat's law. The objective of this paper is to verify whether these empirical regularities shown in the international literature occur in Brazil and to discuss the theoretical aspects of these phenomena. The study uses the Brazilian census data of 1970, 1980, 1991 and 2000 and the 1996 population counting.

This article besides this introduction has three sections. The second section is a digression on the subject and presents the estimated model. The third section presents the results and discussions and the last section presents the conclusions.

\section{Empirical Digression of the City Sizes}

Examining data about the Brazilian cities since 1970, it is possible to establish the existence of a range of sizes and kinds of cities. The objective of this section is to analyze the problem of the relationship between theory and facts.

If we rank cities from largest (rank 1) to smallest (rank $\mathrm{N})$ to get the rank r(p) for a city of size p, then:

$$
\log r(p)=\log A-\beta \log p \text {. }
$$

Zipf (1949) proposed that city sizes follow a special form of the distribution where $\beta=1$. This expression has become known as Zipf's Law ${ }^{2}$.

According to Krugman, Fujita and Venable (2002) attempts to relate economic theory to reality, normally face a problem, as by rule, the theory is usually precise, providing well-defined and simple forecasts, whilst the real world produces complicated and disorganized results. However, when the matter is the the distribution of city sizes, there is an inversion; namely, the facts surprisingly offer a clear picture, which are very difficult to be reproduced theoretically.

Many authors have tried the empirical distribution of city sizes (Carrol 1982, presents survey on this subject)

\footnotetext{
${ }^{1}$ Data from the Brazilian Institute for Geography and Statistics (IBGE). 2 Its deterministic equivalent suggests that the second largest city is half the size of the largest, the third largest city a third the size of the largest etc. When expressed like this, the regularity is often referred to as the rank size rule.
}

but less attention has been given to the explanation of this fact. Amongst the most recent studies are: Eeckhout (2004), Gabaix (1999), Rossi-Hansberg and Wright (2004) and Gabaix and Ioannides (2004). The fact is that the distribution of the biggest American cities according to Krugman, Fujita and Venable (2002) is surprisingly well described by a law of power. The number of cities with a population bigger than $(\mathrm{S})$ is proportional to $\left(\mathrm{S}^{-\mathrm{a}}\right)$, with (a) near to 1 . Plotting the log of the size of the metropolitan areas against the log of the classification yields a nearly perfect line with a $45^{\circ}$ degree angle. A more formal statistical analysis verifies the visual impression.

Dobkins and Ioannides (1996) suggested that the distribution of the American city sizes in the last century was well described by a power law with exponent near to 1. From a more formal point of view, let $N(S)$ be the number of cities with population $S$ or bigger, then the linear regression in the log is

$$
\ln (\mathrm{N})=\mathrm{b}-\mathrm{a} \ln (\mathrm{S})+\mathrm{u}^{3}
$$

Where (a) approaches of 1 . The authors found the value (a) to be 1.0044. Rosen and Resnick (1980) suggest that a power law with not very distant exponent to 1 describes the majority of the distributions of sizes of the national metropolitans and that the exponent approaches more and more to 1 with definition of S.

If in fact a proposition that the city sizes follow a power law with exponent near to 1 , so there must exist an empirical law that explains the distribution of city sizes. It is the called Zipf's Law due to the work of George Zipf (1949). An alternative name for the Zipf's law is the ranksize rule, an empirical regularity found in social sciences. Faced with the empirical regularity of the rank-size rule, what would the economic theory have to say? The theoretical discussions below will attempt to explain this.

The size distribution models can explain the rank-size rule but many objections that appear should be also considered. The models of urban systems like Henderson's generate a size distribution based on the following arguments: the external economies tend to be specific to particular industries, whilst the diseconomies tend to depend on general city sizes, or on what they produce. In other words, there is no point in establishing on the same city industries that generate little or no mutual economy of scale, as they will generate little or no diseconomies of agglomeration. Such as rent and price of lands increases. In this way, each city should be specialized in some industries that create external economies. However, the stretch of the size of these industries can vary according to the type of industry. A textile industry would not have reasons to include more than certain quantity of factories. Meanwhile, other activities such as financial activity would be able to include financial business of a whole nation. Then, the

\footnotetext{
${ }^{3}$ Zipf (1949) proposed that city sizes follow a special form of the distribution where $b=1$. This expression has become known as Zipf's Law. Its deterministic equivalent suggests that the second largest city is half the size of the largest, the third largest city a third the size of the largest etc. When expressed like this, the regularity is often referred to as the rank size rule. The relative empirical regularity suggested by Zipf's law to explain the distribution of the cities has also motivated further research work in order to test Gibrat's Law. Gibrat's law states that the growth rate of the cities is not correlated to their size.
} 
city sizes will depend on their roles (Fujita, Krugman, and Venables, 2002).

However, how can we verify that Henderson's model can generate similar results to the power law? Alternatively, how can Henderson's model be able to generate a distribution of city sizes from the tension amongst economies of scale, external diseconomies, cost of transport and the effects of technology and communication? It could hardly generate a fixed size distribution as suggested empirically by the rank-size rule. The empirical regularity presents a challenge to the answers for such results.

Fujita, Krugman and Venables (2002) discuss some possible theoretical alternatives: random growth, Simon's model and Gibrat's Law, which will be discussed next.

In which form could Simon's model be able to explain the rank-size rule? Rewriting it in a different way, it is possible to say that the density of the city sizes is:

$$
\mathrm{n}=\mathrm{akS}^{-\mathrm{a}-1}
$$

In this way, the elasticity of the density of the cities with regard to the size is:

$$
\mathrm{a}-1: \mathrm{dn} / \mathrm{ds} \times \mathrm{S} / \mathrm{n}=-\mathrm{a}-1
$$

By worrying about the empirical regularity of power law with regards to the city sizes with a relatively stable exponent in all time and space, the Simon model nevertheless represents an improvement to the economic models by Fujita, Krugman and Venables (2002). The three reasons are: it foresees the power law that the central-place theory does not; the parameter that decides the power law is the probability of formation of a new city and finally the mysterious exponent 1 can be naturally interpreted as the increase of turban population that moves to existing cities instead of forming new cities. Despite these improvements, the lack of economic appeal of Simon model reduces it to nearly a simple explanation of a regularity of the power law concerning city sizes.

Gabaix (1997) shows that the Zipf's Law could also give rise to Gibrat's Law. He assumes that both the expected growth rate and the variance of this growth rate in some ranges of cities sizes should not be correlated. This produces a distribution in fix state that approximates to power law for this range with exponent equal to 1 . Fujita, Krugman and Venables (2002) question if in fact this would be a solution for the enigma. The fact that Gibrat's Law requires that the variance of the growth rate be independent of the city size makes it more difficult to understand. If a city consists of a simple group of industries, without positive or negative flows between them, the variance of the growth rate should diminish with the city size because of the question of diversification. In this case, the economic aspect of the phenomenon continues enigmatic.

Krugman (1997) attributes this fact to the randomness that creates the power law, namely, the power law may not involve a random growth but random connections in the space. This theoretical line of argument supported by the percolation models, well studied in the physics and which easily produce the power laws. For instance, the distribution of the size of the rivers, measured by the volume of stream, adapts to the Zipf's Law. In this way, the percolation model is able to provide means of overcoming the problems of the Simon's model.
Fujita, Krugman and Venables (2002) also point to the possibility of a hierarchical system in which the growth of the economy containing many industries of different orders is able to create a hierarchical urban system. Despite the existence of the formalization of model, they have not been able to present an analytic verification of the model, they have only managed to present some figures using numerical simulations. In this model, extending the analysis from a simplified model of monopolar special structure to the evolution of how the spatial system develops in the long term, the results point to the formation of cities, occasional extinction of cities and urban redevelopment, producing a hierarchical system. In this model, three possible kinds of cities exist: the highest order, which includes all three types of industries; the intermediate order, which includes industries types 1 and $2^{4}$; and the lowest order, which includes the industries of type 1 only $^{5}$. The intuitive appeal of the model shows that the hierarch can arise from a decentralized market process. The differences between the industries in scale economies and/or the costs of transport define a classification in terms of the tension between the appeal of scattered consumers and the collections they establish. Consequently, this classification of industries leads to a hierarchy of cities where the larger order cities present a bigger range of industries comparatively to the smaller order cities. The model helps us to understand as to why in practice it is not possible to identify a so-called typical city size, as the distribution of size is very broad and does not show signs of aging.

An alternative approach, with economic appeal, is presented by Fujita and Thisse (2002) when dealing with the possibility of emergence of new cities, ceasing the configuration monocentric. A summary of the model is defined as follows: even assuming that the agglomerative effects do not exist, certain locations become attractive because firms may have access to big markets that can even be located in cities in the interior. With the displacement of a small number of firms, agglomerations trigger a mechanism that leads to the creation of new cities. On the contrary, simultaneously, the contraction mechanism works in favor of existing cities preventing them to disappear.

Finally, Anas and Xiong (2002) aim at an alternative model that includes the service sector. A summary of the model is described as follows: the diversification of cities is explained without the imposition of connections between industries. In each one of the industrial cities, a manufactured item is competitively produced utilizing work and industrial service differentiated for specific inter-industries. The industrial sector imports service from all the cities that produce them, since technology favors diversification. In specialized cities, the industrial cities are big and many services are locally available but the industries should trade between the cities. In the diversified cities, the two kinds of items are produced in the same city, and each industry absorbs half of the local service, but manufactured items do not need to be imported. A smaller cost of transport of the industrialized

\footnotetext{
${ }^{4}$ For details refer to Fujita, Krugman and Venables (2002).

${ }^{5}$ EASTERLY and R ESHEF (2009). Apply this method in the study of exports. Di GIOVANNI et al (2010) apply this method in the study of exports and size of firms. Justo (2012) apply this method to other Brazilian cities considering sizes of cities and other period.
} 
products (through highways and interlinks between the cities) favor a system of specialized cities, whilst a small cost of the service of commerce (for instance, telecommunications and the Internet) favors a diversified system of cities as they rely more and more on imported services, since less exists locally. The bigger participation of the specialized services, the higher the cost of connections between the cities and population growth favors the diversification.

\section{Results and Discussions}

Regarding the theoretical argument for explaining the distribution of cities, it is possible to observe the behavior of the distribution of the Brazilian cities with at least
50,000 inhabitants between 1970 and 2000 in the Table 1 . In 1970, 240 cities with this profile existed and in 2000, this number increased to 503. The distribution of these cities was almost maintained in the five Brazilian regions during this period, namely, in 1970, $41.76 \%$ of the cities with at least 50,000 inhabitants situated in the Southeast region, the one with largest participation and in 2000 it corresponded to $43.34 \%$, still maintaining its leadership in terms of regional distribution. The region that presented the smallest participation in the number of cities with this profile was Center-West region with $4.40 \%$, in 1970 and in 2000 its participation was of 5.37\%. Both the Northeast and South regions lost relative participation in the number of cities in this period.

Table 1. Number of Cities with At Least 50,000 Inhabitants by Region: 1970-2000

\begin{tabular}{|c|c|c|c|c|c|c|c|c|}
\hline \multirow[b]{2}{*}{ Region } & \multicolumn{2}{|c|}{1970} & \multicolumn{2}{|c|}{1980} & \multicolumn{2}{|c|}{1991} & \multicolumn{2}{|c|}{2000} \\
\hline & Qde. & \% Total & Qde. & $\%$ Total & Qde. & \% Total & Qde. & $\%$ Total \\
\hline Center-West & 11 & 4.40 & 16 & 4.40 & 21 & 4.65 & 27 & 5.37 \\
\hline Northeast & 70 & 27.47 & 100 & 27.47 & 128 & 28.32 & 137 & 27.24 \\
\hline North & 7 & 6.59 & 24 & 6.59 & 32 & 7.08 & 38 & 7.55 \\
\hline Southeast & 101 & 41.76 & 152 & 41.76 & 191 & 42.26 & 218 & 43.34 \\
\hline South & 51 & 19.78 & 72 & 19.78 & 80 & 17.70 & 83 & 16.50 \\
\hline Brazil & 240 & 100.00 & 364 & 100.00 & 452 & 100.00 & 503 & 100.00 \\
\hline
\end{tabular}

Source: Own elaboration based on data from IBGE.

A look into the distribution of the Brazilian population living in cities with at least 50,000 habitants shows that between 1970 and 2000 there was a convergence of the population in the cities with this profile, as noted by the growth of the participation of the population in the towns

with that profile in comparison to the total Brazilian population in the same period. This result can be seen in the Table 2 where in $197044.63 \%$ of the Brazilian population resided in towns with at least 50,000 inhabitants, and number increased to $62.11 \%$ in 2000 .

Table 2. Percentage of the Brazilian Population living in Cities with At Least 50,000 Inhabitants

\begin{tabular}{|c|c|c|c|c|}
\hline & 1970 & 1980 & 1991 & 2000 \\
\hline (a) Brazil & 93.134 .846 & 119.011.052 & 146.825 .475 & 169.799.170 \\
\hline (b) Cities with 50,000 Inhabitants & 41.567 .226 & 66.740 .350 & 88.593 .723 & 105.467 .293 \\
\hline$\%$ (b/a) & 44.63 & 56.08 & 60.34 & 62.11 \\
\hline
\end{tabular}

Source: Own elaboration based on data from IBGE.

Analyzing the behavior of the growth rate of the population in towns with at least 50,000 inhabitants and comparing it with the growth rate of the Brazilian population as a whole, it is possible to observe similar results despite the difference of magnitude. In other words, the facts indicate a decrease in the population growth rates as a whole as well as in the cities with at least 50,000 inhabitants. However, the population growth rate has always maintained itself above the latter in comparison to the former (Table 3). Between 1970 and 1980, the Brazilian population grew by $27.78 \%$ while the population in the cities with at least 50,000 inhabitants grew by 49.75\%. In the 1991/2000 period, however, the Brazilian population grew by $15.64 \%$, while the population in the cities with at least 50,000 inhabitants grew by $19.04 \%$. This means that while the relationship between the annual growth rates was of 1.96 in the $1970 / 80$ period, this decreased to 1.20 in the $1991 / 2000$ period. This result shows that although the growth in the participation of the population living in cities with at least 50,000 inhabitants remains, the growth rate has slowed down. The reason is in part due to the adjustment in the rapid urbanization development of the population that started more slowly in the 60's and accelerated in the 70's. This also reflects the influence of commercial liberalization process that occurred in this period. According to Maciel (2003), this process interiorized the development, stimulating the growth of many cities in several regions of the country. It is possible that this phenomenon has also contributed to the increase of the participation of the cities with at least 50,000 inhabitants in relation to the total population. The 
inter-regional migration has also played an important role in the phenomenon.

Table 3. Annual Growth Rate: Total population and Population Living in Cities With At Least 50,000 Inhabitants

\begin{tabular}{c|c|c|c|c|c|c}
\hline \multirow{2}{*}{ Table 3. Annual Growth Rate: Total population and Population Living in Cities With At Least 50,000 Inhabitants } \\
\cline { 2 - 8 } & \multicolumn{2}{|c|}{$1980 / 70(\%)$} & \multicolumn{2}{|c|}{$1991 / 80$ (\%) } & \multicolumn{3}{|c}{$2000 / 1991$ (\%) } \\
\cline { 2 - 8 } Brazil & Annual & Total & Anual & Total & Anual & Total \\
\hline Cities with 50,000 or more Inhabitants & 2.48 & 27.78 & 1.93 & 23.37 & 1.63 & 15.64 \\
\hline
\end{tabular}

Source: Own elaboration based on data from IBGE.

Once a short descriptive analysis of the distribution of the Brazilian cities has been made, the study now moves to a more specific analysis, which involves the application of both the Zipf's and Gibrat's laws to the Brazilian cities.

The Zipf's law has been presented in the literature in two forms: adjusted regressions and through graphics. In this article both forms are applied to the the distribution of Brazilian city sizes. The cities are ranking in decreasing order of their size and the Zipf's Law is applied, considering several sizes of S, namely, by adjusting the regressions with values of $S$ equal to 50,$000 ; 100,000$ and

200,000 inhabitants respectively, distributed over the years of 1970, 1980, 1991 and 2000.

In Table 4, it is possible to observe the values of the adjusted coefficients of the regressions considering $\mathrm{S}$ equal to 50,000 inhabitants. For all of the years the values of the coefficients were significant to $1 \%$. An observed regularity is that the values of the coefficients, in absolute terms, decreases as the years advance and the number of cities increases. Rose (2005) also found similar results in a study of American cities.

Table 4. Zipf's Law for Cities with at Least 50,000 Inhabitants: Dependent variable - Ln N

\begin{tabular}{cccccc}
\hline & 1970 & 1980 & 1991 & 2000 \\
\hline Constant & $19.1807^{*}(0 . .4607)$ & $19.2456^{*}(0.2128)$ & $19.1996^{*}(0.0092)$ & $19.0236^{*}(0.0818)$ \\
LnS & $-1.2757^{*}(0.0405)$ & $-1.241796^{*}(0.0187)$ & $-1.212014^{*}(0.1052)$ & $-1.1818^{*}(0.0072)$ \\
$\mathrm{F}$ & 989.59 & 4422.65 & 17314.23 & 27162.48 \\
\hline Number of Observations & 241 & 364 & 448 & 500 \\
$\mathrm{R}^{2}$ & 0,75 & 0,76 & 0,83 & 0,81 \\
\hline
\end{tabular}

Source: Own elaboration based on data from IBGE.

* Significant to $1 \%$

** robust errors standards

In Figure 1, Figure 2, Figure 3 and Figure 4, it is possible to observe the distribution of the Brazilian cities with at least 50,000 inhabitants in the years 1970, 1980, 1991 and 2000.

Some peculiar results can be observed in the Figure 1, in particular concerning the hierarchy, where in 1970
Fortaleza was in a position below Recife and Porto Alegre, indicating it had a lower population. Recife also presented a population greater than Salvador.

It is possible to observe in the Figure 1 that, in fact, the empirical regularity of the distribution of city sizes occurs according to Zipf's Law.

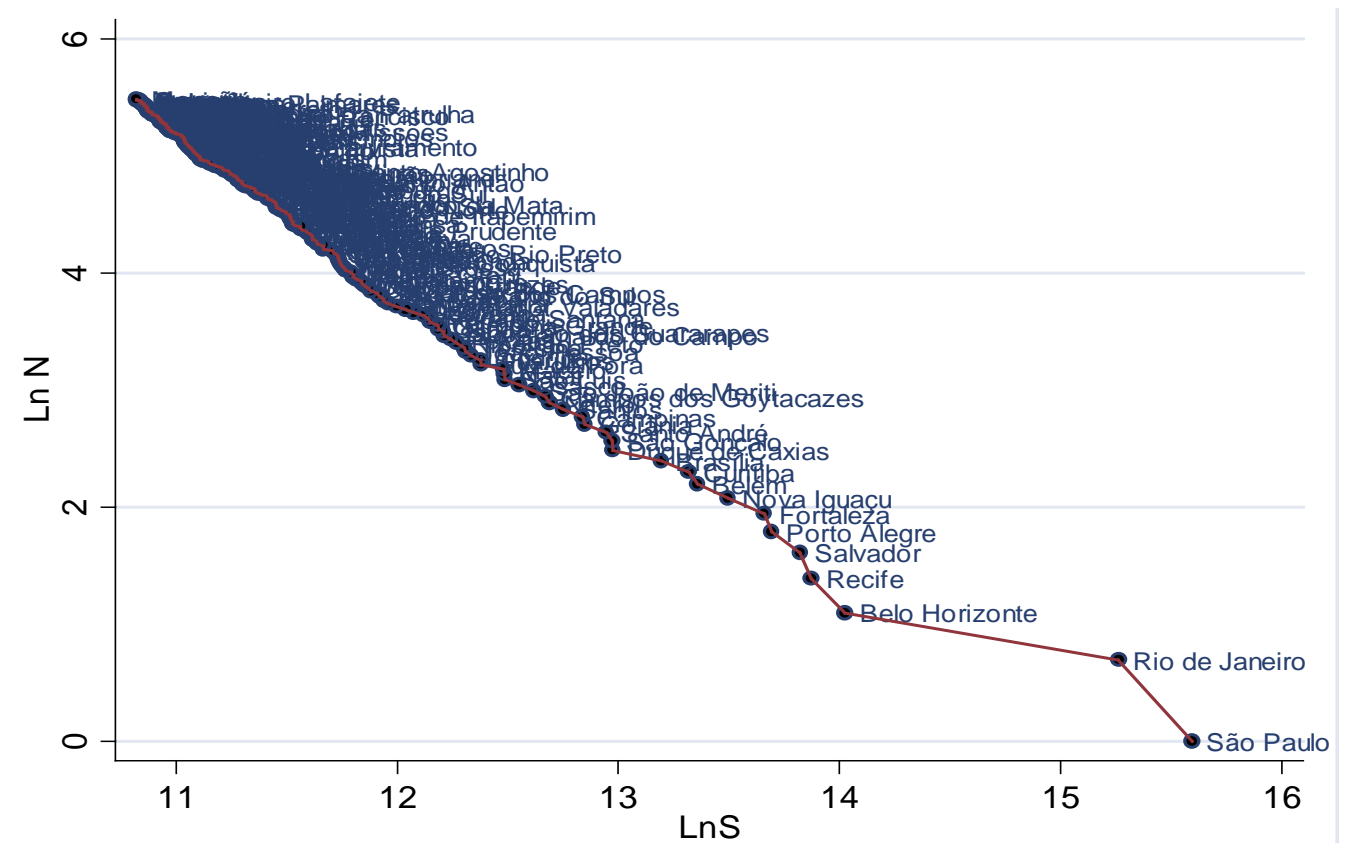

Figure 1. Distribution of the Brazilian Cities with At Least 50,000 Inhabitants: 1970

Source: Own elaboration based on data from IBGE.

Figure 2 also shows a relative application of Zipf's Law to the distribution of the Brazilian cities in 1980 with at least 50,000 inhabitants. It is possible to observe in this case that amongst the largest Brazilian cities changes of raking as regards the order of city size, namely, both Salvador and Fortaleza overtook Recife. Another important change is the population growth of Brasília that in 1980 presented a larger population than Porto Alegre. 


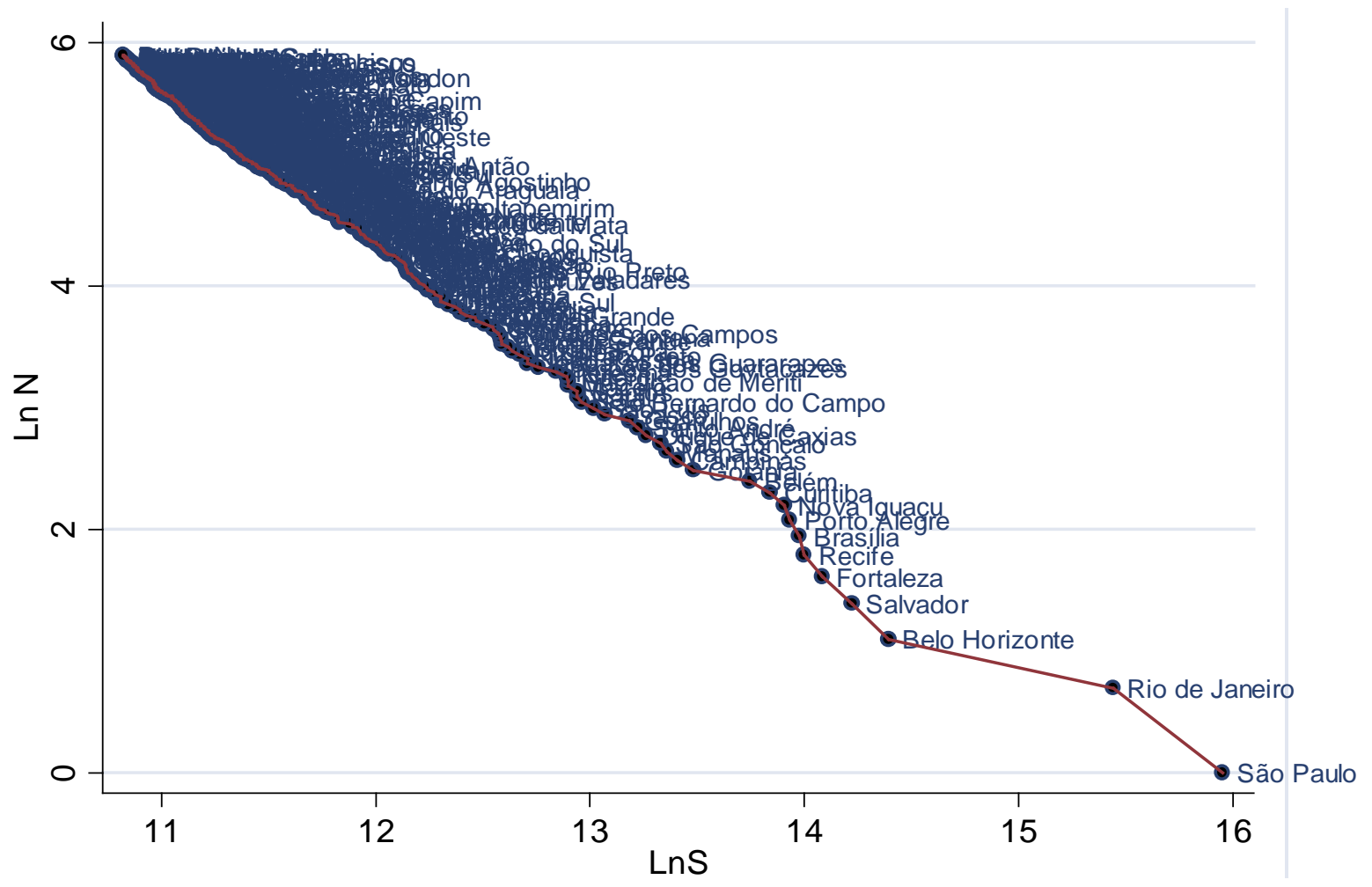

Figure 2. Distribution of the Brazilian Cities with At Least 50,000 Inhabitants: 1980

Source: Own elaboration based on data from IBGE.

Again, it is possible to verify the relative application of the Zipf's Law to the distribution of the Brazilian cities with at least 50,000 inhabitants, with the 1991 data, presented in Figure 3.
In Figure 3 is also possible to observe some changes in the ranking of the biggest Brazilian cities; that is; Salvador has become the third largest Brazilian city, Fortaleza the fourth and Brasilia the fifth. Curitiba has also overtaken Recife.

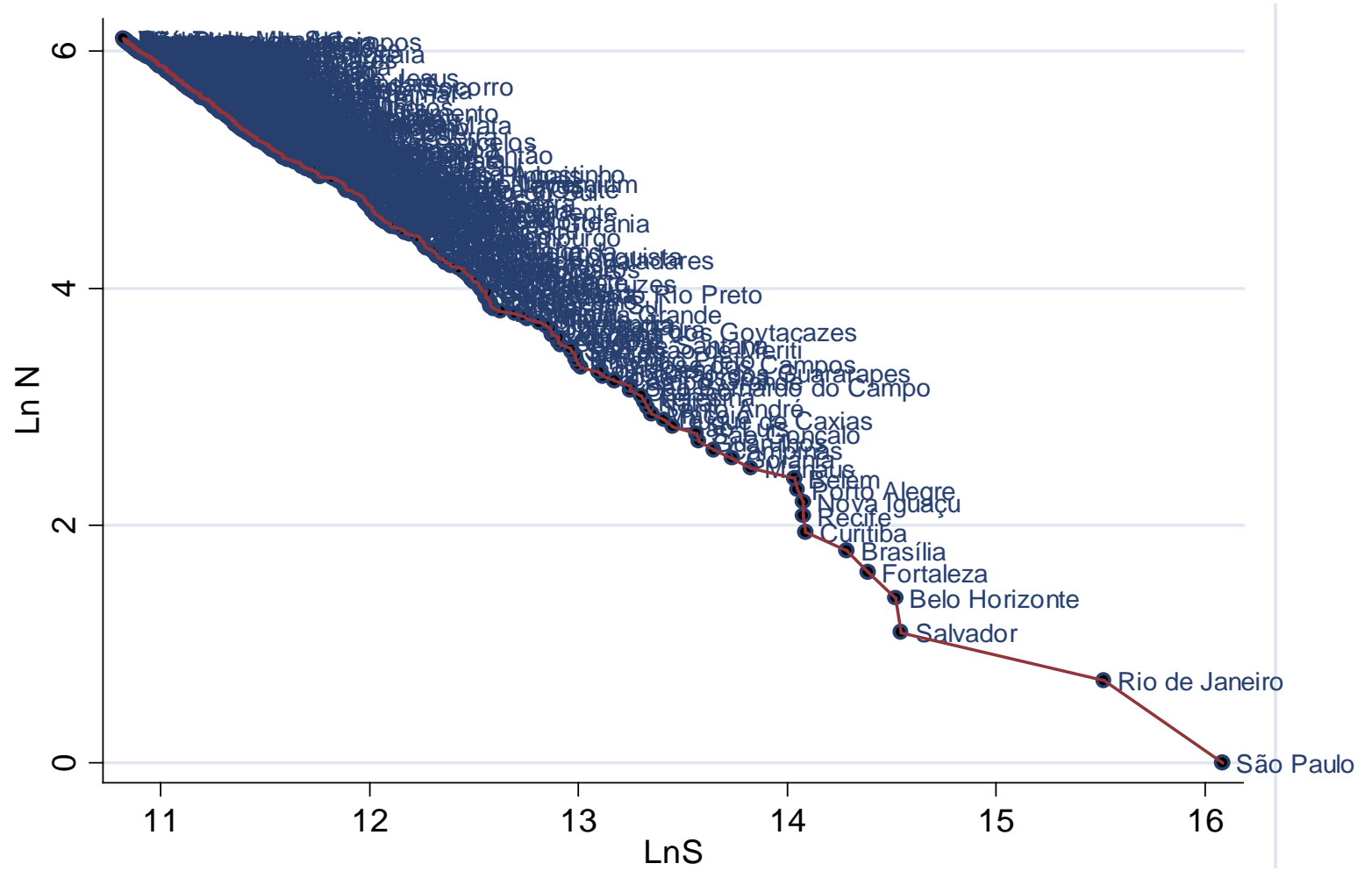

Figure 3. Distribution of the Brazilian Cities with At Least 50,000 Inhabitants: 1991

Source: Own elaboration based on data from IBGE.

In 2000, the main change of position in the order of population size amongst the biggest Brazilian cities is Manaus surpassing Porto Alegre. Another change observed in Figure 4 is the reduction in the difference between Fortaleza and Belo Horizonte, indicating that at this growth rate, Fortaleza should surpass Belo Horizonte. 


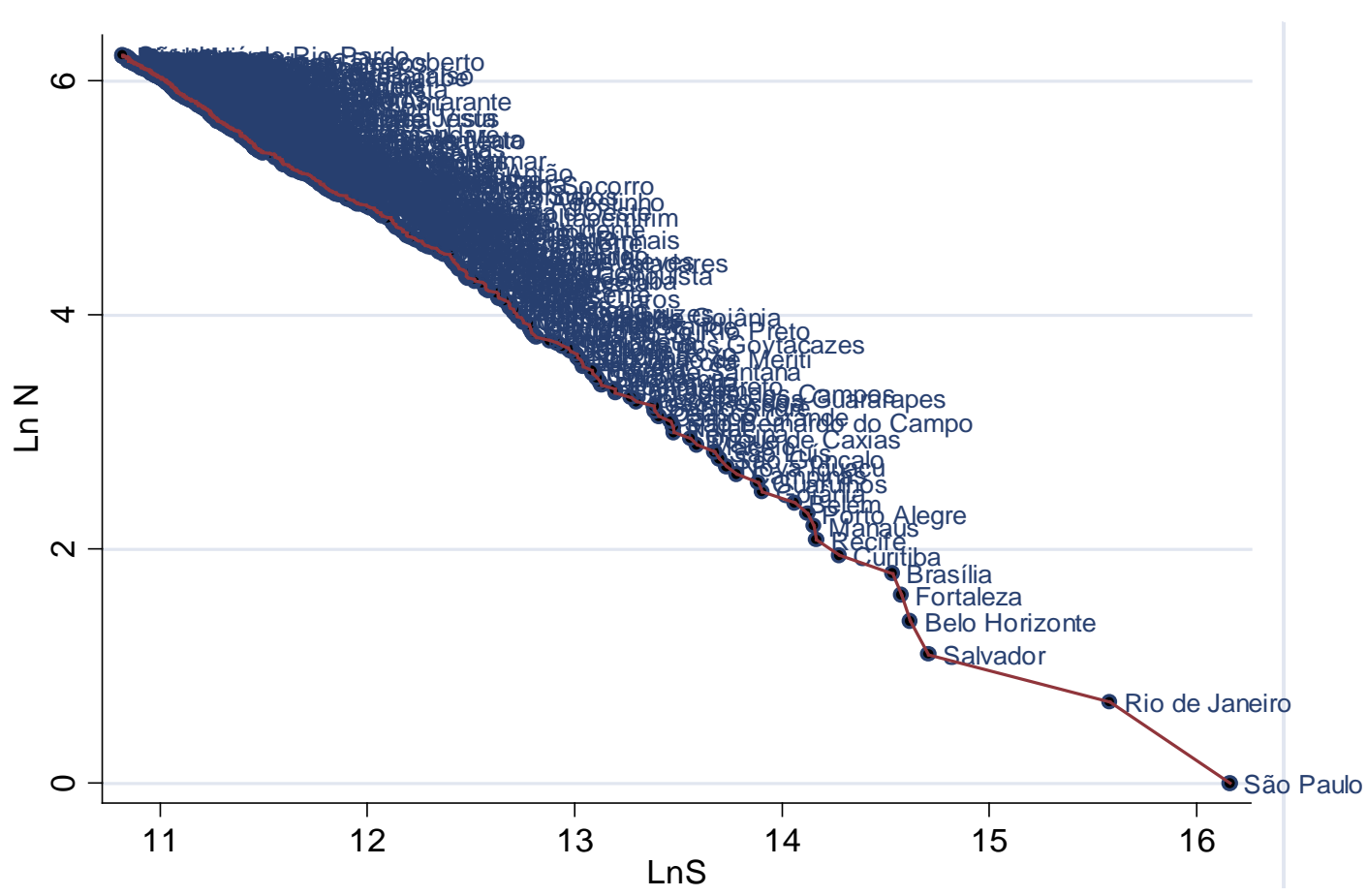

Figure 4. Distribution of the Brazilian Cities with At Least 50,000 Inhabitants: 2000

Source: Own elaboration based on data from IBGE.

The estimates were repeated varying the size of $S$ in order to verify whether Zipf's Law would still explain the distribution of the Brazilian cities. As it can be observed in Table 5, increasing the value of $\mathrm{S}$ for cities with at least 100,000 inhabitants, the value of the estimated coefficients are significant to $1 \%$. There is not a tendency for the decrease in the absolute value of the coefficients, as it was observed when the value of $\mathrm{S}$ was of 50,000 inhabitants. On the contrary, the values of the coefficients increase with the rise in the number of cities that occurs during the years.

Table 5. Zipf's Law for Cities with at Least 100,000 Inhabitants: Dependent variable - Ln N

\begin{tabular}{c|ccc|c}
\hline & 1970 & 1980 & 1991 & 2000 \\
\hline Constant & $17.5541^{*}(0.6339)$ & $18.6327^{*}(0.3974)$ & $19.2552^{*}(0.2398)$ & $19.5593^{*}(0.1717)$ \\
LnS & $-1.147671^{*}(0.0528)$ & $-1.1931^{*}(0.0328)$ & $-1.2160^{*}(0.0197)$ & $-1.2233^{*}(0.0141)$ \\
F & 473.23 & 1320.04 & 3795.78 & 7553.10 \\
\hline Number of Observation & 90 & 137 & 182 & 217 \\
$\mathrm{R}^{2}$ & 0,73 & 0,75 & 0,81 & 0,82 \\
\hline
\end{tabular}

Source: Own elaboration based on data from IBGE.

* Significant to $1 \%$

** Robust error standards

The behavior of the values of the coefficients when the value of S passes for 200,000 inhabitants is similar to the value of $S$ is 100,000 . This means that it grows with the

increase of the number of cities. As it can be observed in the Table 6 , all of coefficients are significant to $1 \%$.

Table 6. Zipf's law for Cities with at Least 200,000 Inhabitants: Dependent variable - Ln N

\begin{tabular}{c|ccc|c}
\multicolumn{7}{c}{ Table 6. Zipf's law for Cities with at Least 200,000 Inhabitants: Dependent variable - Ln N } \\
\hline & 1970 & 1980 & 1991 & 2000 \\
\hline Constante & $15.9049^{*}(0.8752)$ & $17.6845^{*}(0.6216)$ & $19.1967^{*}(0.47212)$ & $20.1964^{*}(0.4296)$ \\
LnS & $-1.02478^{*}(0.0689)$ & $-1.1230^{*}(0.0489)$ & $-1.2120^{*}(0.0371)$ & $-1.2714^{*}(0.0336)$ \\
F & 220.89 & 528.19 & 1066.84 & 1430.17 \\
\hline Número de Observações & 32 & 55 & 85 & 106 \\
$\mathrm{R}^{2}$ & 0,72 & 0,71 & 0,73 & 0,78 \\
\hline
\end{tabular}

Source: Own elaboration based on data from IBGE.

* Significant to $1 \%$

** Robust errors standards

The results show that, although the limit is higher than the one obtained in developed countries, Zipf's Law is observed in the distribution of the size of the Brazilian cities along the studied period.

The relative empirical regularity suggested by Zipf's law to explain the distribution of the Brazilian cities has also motivated further research work in order to test Gibrat's Law for the Brazilian case.

Gibrat's law states that the growth rate of the cities is not correlated to their size. The results presented in the

Table 8 show that considering the 50 largest Brazilian cities in 2000 and calculating the growth rate of the population between 1996 and 2000 for these cities, Gibrat's law applies well to the distribution of the size of the largest Brazilian cities. The log coefficient of the population of the 50 biggest Brazilian cities is not significant to $1 \%$.

In order to verify the possibility that Gibrat's law would be able to explain Zipf's law, as discussed in the section 2, it was developed a model in which the dependent variable 
is the variance of the population growth rate and the explanatory variable is the log of the population of the 50 biggest Brazilian cities. The results can be seen in Table 7 . In fact, as the coefficient of the log of the population is not significant, there is no correlation amongst the variables, which makes question more enigmatic.

Table 7. Gibrat's Law with the $\mathbf{5 0}$ Biggest Brazilian Cities in $\mathbf{2 0 0 0}$

\begin{tabular}{ccc}
\hline $\begin{array}{c}\text { Depedent Variable: Population } \\
\text { Growth Rare }\end{array}$ & $\begin{array}{c}\text { Dependent variable: Variance of the } \\
\text { Population growth rate }\end{array}$ \\
\hline Constant & 1,881 & $17,31916^{*}$ \\
Log of Population in & $(2,324)$ & $(4.464367)$ \\
1996 & 0,0308 & $-0,7388491$ \\
F & $(0,397)$ & $(0,7422086)$ \\
$\mathrm{R}^{2}$ & 0,94 & 0,99 \\
\end{tabular}

Source: Own elaboration based on data from IBGE.

*Significant to $1 \%$

** Robust errors standards

The Figure 5 shows the application of Gibrat's Law, considering the 50 largest Brazilian cities. Rose (2005) found similar results for the biggest American cities in the period 1990-2000.

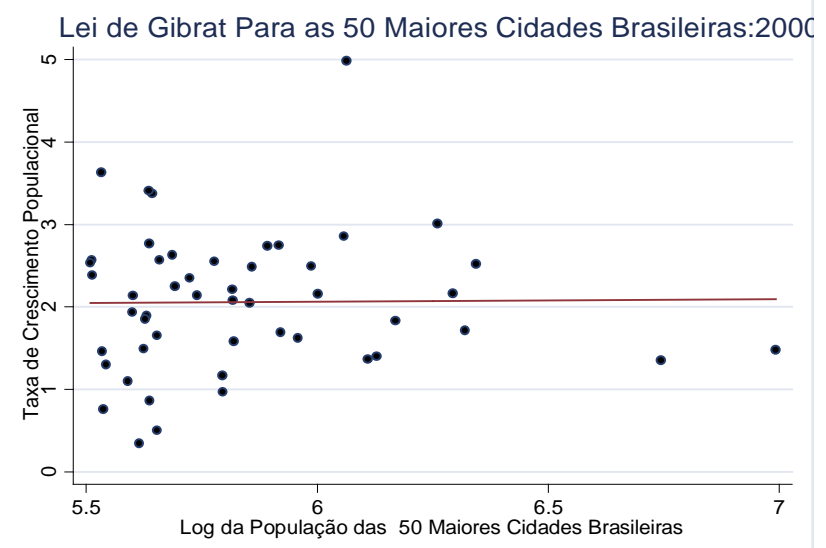

Figure 5. Gibrat's Law for the 50 Biggest Brazilian Cities: 2000

Source: Own elaboration based on data from IBGE.

Faced with such results, the question is which of the theoretical models discussed in the section 2 would be able to support such results. As previously discussed, the verification of the empirical regularity of the Zipf's Law makes the distribution of the size of the Brazilian cities intriguing. This is despite the fact that Brazil presents a series of singularities not found in developed countries, and may have passed by a series of changes in its economy in the last decades with adverse effects on the five Brazilian regions, which makes difficult to find a unique theoretical model that explains such behavior.

Just to illustrate some of the phenomena that affected the Brazilian economy since 70's and that, possibly may help to explain the distribution of the Brazilian cities, there is the period of the Brazilian miracle that consolidated the industrial park in the Southeast and some infrastructure investment that subsequently improved the growth in several Brazilian regions.

During the 80 's, as a result of the oil crisis and the problems with external account, consistent regional policies became secondary and were responsibilities of the individual states with their own distinct policies. Allied to that phenomenon, there is the consolidation of the petrochemical complexes of Camaçari in Bahia and the textile centre of Fortaleza with consequences to the economies of some cities of these states, in particular to those belonging to the respective metropolitans regions.

During the 90's, the commercial liberalization had different repercussions in the economy of several Brazilian towns and regions. For instance, the majority of towns with annual population growth of more than 5.0\% were in the State of Mato Grosso, followed by Pará and São Paulo. On the other hand, areas with decrease in population include the extreme north of the Rio Grande do Sul State, the west of Santa Catarina, in areas near to the border with the Argentina. Another area characterized by the population decrease consists the towns of the central of the State of the Paraná, near to the border with the Paraguay, in the axis of the interstate $\mathrm{BR}^{6} 385$ and, a corridor formed by towns of the States of Minas Gerais and Bahia, between the BR 101 and 116 (IBGE, 2004).

Another important factor that, allied to the consequences of the commercial liberalization, has influenced the population distribution and the distribution of the cities is the intensification of the "fiscal war" between the states, which due to the lack of a national regional policies tried to attract investments. These investments represent many times the simply displacement of manufacturing units from one city to another to take advantage of the fiscal incentives granted.

Finally, it is still possible to observe in Brazil, the consolidation of agricultural borders, in particular in the Cerrado region and the occupation of part of the Amazon region with activities related to exporting agrobusiness, which have changed the population profile of various regions. For instance, the productive chain of soy beans in the states of Mato Grosso, Mato Grosso do Sul, Minas Gerais, Goiás and west of the Bahia; of cotton in the state of Mato Grosso and west of Bahia; productive chain of the beef and pig in state of Goiás and Mato Grosso, among others.

Finally, it is important to mention the acceleration of the urbanization process of the Brazilian population in the last decades that jointly with some of the phenomena previously mentioned explains, in part, the results founded.

\section{Conclusions and Final Considerations}

Despite the attempts to relate the economic theory with the facts, as a rule whilst the theory is precise, generating well-defined and simple forecasts, the real world produces results complicated and disorganized, regading the distribution of city sizes, there is an inversion. The facts surprisingly offer a sharp picture, which are difficult to be reproduced theoretically.

In this direction, this work tried to verify if two of the most known and intriguing phenomena, Zipf's law and Gibrat's law, widely discussed in international literature occur in Brazil. At the same time to present a theoretical discussion about such phenomena. The results suggest that these empirical regularities occur in the distribution of the Brazilian cities despite various simulations considering city sizes.

The results also have shown changes in the ordering of the largest Brazilian cities, as Salvador and Fortaleza went

\footnotetext{
${ }^{6}$ Brazilian national highways.
} 
up in the ranking of the largest cities in the last three decades and Recife lost some positions.

The next step of this work would be to verify in more detail whether the distribution of the cities in regional terms are identified by the factors that had led to the space occupation of the Brazilian territory with the increase of the participation of the population inhabiting cities with at least 50,000 inhabitants. This has happened despite significant changes that occurred in the Brazilian and world economies with direct and indirect nonhomogeneous effects amongst the Brazilian regions and cities.

\section{References}

[1] ANAS, Alex and XIONG, Kai.. "Intercity Trade and the Industrial Diversification of Cities". Journal of Urban Economics 54, Elsevier B.V., 2002, p. 58-276.

[2] BAIROCH, P. Economics and World History: Myths and Paradoxes. Chicago: The University Press, 1993.

[3] CARROL, G. "National city size distributions: What do we know after 67 years of research” Progress in Human Geography 6, 1982, p. 1-43.

[4] Di GIOVANNI, J.; LEVCHENKO, A. A.; RANCIERE, R. Power laws in firm size and openness to trade: Measurement and implications. University of Michigan, manuscript, Mar. 2010. 29 p.

[5] DOBKINS, L. H. and IOANNIDES, Y.M. Dynamic evolution of the size distribution of U.S. cities. In: J. M. Huriot and J.-F. Thisse (eds). Economics of Cities. Cambridge: University Press, 2000, p. 217-60.

[6] EECKHOUT, Jan. “Gibrat's Law for (All) Cities”. American Economic Review, 94-5, 2004, p. 1429- 1451

[7] EASTERLY, W.; RESHEF, A. Big hits in manufacturing exports and development. NYU, manuscript, Oct. 2009. 49 p.
[8] FUJITA, M. and TABUCHI, T.. Regional growth in postwar Japan. Regional Science and Urban Economics 30, Elsevier, B.V, 1997, p. 643-70

[9] FUJITA, M., KRUGMAN, P. and VENABLES, A. Economia Espacial: urbanização, prosperidade econômica e desenvolvimento humana. São Paulo: Futura, 2002.

[10] FUJITA, $\mathrm{M}$ and THISSE, Jacques-François. Economics of Agglomeration: Cities, Industrial Location, and Regional Growth. Cambridge University Press, 2002.

[11] GABAIX, X. "Zipf's law for cities: An explanation”. Harvard University, Cambridge, MA, 1997.

[12] HENDERSON, J.V. (1997). Medium size cities. Regional Science and Urban Economics 27, Elsevier B.V., 1997, p. 583-612.

[13] IBGE. Tendências demográficas: uma análise dos resultados da amostra do Censo Demográfico de 2000. IBGE, Rio de Janeiro, 2000.

[14] JUSTO, W. R. A Century of Growth of the Brazilian Cities: A space approach, 1910-2010, In: ANPEC, 2012.

[15] KRUGMAN, P. "What Should Trade Negotiators Negotiate About?” Journal of Economic Literature 35, 1997, p. 113-120.

[16] MACIEL, V. F. (2003). Abertura Comercial e desconcentração das metrópoles e capitais brasileiras. Revista de Economia Mackenzie 1, São Paulo, 2003, p. 39-64.

[17] NITSCH, Volker (2005). "Zipf Zipped". Journal of Urban Economics 57, Elsevier B.V., 2005, p. 86-100.

[18] ROSE, Andrew K (2005). “Cities and Countries”. NBER Working Paper, 11762, 2005.

[19] ROSSI-HANSBERG, E. and Wright, M. Urban structure and growth. Working paper Stanford, Department of Economics, Stanford University, 2004.

[20] ZIPF, G. K. Human Behavior and the Principle of Least-Effort. Addison-Wesley, Cambridge, MA, 1949.

[21] MAGAlHÃES, M. A de, TOSCANO, V.N. Assimetria e concentração: um estudo empírico da distribuição de investimentos previstos para o Estado do Espírito Santo, 20092014. Nova Economia_Belo Horizonte 22 (2) 333-377 maioagosto de 2012. 